\title{
Causes and Solutions of Endovascular Treatment Failure
}

\section{Byung Moon Kim}

Interventional Neuroradiology Severance Hospital Stroke Center, Department of Radiology, Yonsei University College of Medicine, Seoul, Korea

In a meta-analysis of individual patient data from 5 randomized controlled trials, endovascular treatment (EVT) mainly using a stent retriever achieved successful recanalization in $71.1 \%$ of patients suffering from acute stroke due to anterior circulation large artery occlusion (LAO). However, EVT still failed in $28.9 \%$ of LAO cases in those 5 successful trials. Stent retriever failure may occur due to anatomical challenges (e.g., a tortuous arterial tree from the aortic arch to a target occlusion site), a large quantity of clots, tandem occlusion, clot characteristics (fresh versus organized clots), different pathomechanisms (embolic versus non-embolic occlusion), etc. Given that recanalization success is the most important factor in the neurological outcome of acute stroke patients, it is important to seek solutions for such difficult cases. In this review, the basic technique of EVT is briefly summarized and then various difficult cases with diverse conditions are discussed along with suggested solutions.

Keywords Acute stroke; Endovascular thrombectomy; Stent retriever

\author{
Correspondence: Byung Moon Kim \\ Interventional Neuroradiology \\ Severance Hospital Stroke Center, \\ Department of Radiology, Yonsei \\ University College of Medicine, 50-1 \\ Yonsei-ro, Seodamun-gu, Seoul \\ 03722, Korea \\ Tel: +82-2-2228-2399 \\ Fax: +82-2-393-3035 \\ E-mail:bmoon21@hanmail.net; \\ bmoo21@yuhs.ac \\ Received: February 8, 2016 \\ Revised: March 22, 2017 \\ Accepted: April 18, 2017 \\ This research was supported by a \\ grant of the Korea Health Technology \\ R\&D Project through the Korea Health \\ Industry Development Institute \\ (KHIDI), funded by the Ministry of \\ Health \& Welfare, Republic of Korea \\ (HC15C1056).
}

The author has no conflicts of interest.

\section{Introduction}

Based on the success of 5 randomized controlled trials, endovascular treatment (EVT) using a stent retriever (SR) is now recommended as the first-line treatment for acute stroke due to intracranial large artery occlusion (LAO) of the anterior circulation. ${ }^{1-11}$ As a result, the ability to perform an SR thrombectomy is an essential skill for neurointerventionalists, where the learning curve is relatively short for usual cases of EVT. ${ }^{12}$ However, in a meta-analysis of the data of individual patients treated with Solitaire from randomized controlled trials, EVT achieved successful recanalization (modified Tissue Thrombolysis in Cerebral Ischemia [mTICl] 2b-3) in 71.1\% of cases using SR for acute stroke due to anterior circulation LAO. ${ }^{13}$ Conversely, SR throm- bectomy still failed in $28.9 \%$ of the acute stroke cases due to LAO. Although the recanalization rate has been continuously improving thanks to technical developments, EVT failure still occurs in approximately 20-25\% of LAO cases for various reasons in Korea (unpublished data from Korean multicenter registry, 765 patients between September 2010 and December 2015). EVT failure may result from anatomical challenges (e.g., a tortuous arterial tree from the aortic arch to a target occlusion site), a large quantity of clots, tandem occlusion, clot characteristics (fresh versus organized clots), different pathomechanisms (embolic versus non-embolic occlusion), etc. ${ }^{14}$ In this review, the basic procedure of an SR thrombectomy is briefly reviewed, and then problem-solving techniques are suggested for various complicated situations and refractory cases. 


\section{Basic Technique of Stent Retrieval}

\section{Guiding catheter placement}

In an SR thrombectomy for a typical case of acute $L A O$, a large bore ( $8 \mathrm{~F}$ or $9 \mathrm{~F}$ ) balloon guide catheter $(\mathrm{BGC})$ is preferred over a conventional guide catheter, as a BGC improves the recanalization rate and clinical outcome. ${ }^{14-16}$ Inflation of the BGC arrests the downstream blood flow and thus prevents distal embolization of captured clots during the retrieval of the clots engaged by the SR. ${ }^{16,17} \mathrm{~A}$ coaxial technique is invariably easier than an exchange technique for BGC placement. For the coaxial tech-

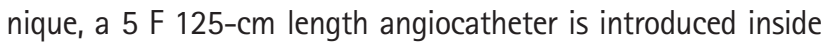
an $8 \mathrm{~F}$ or $9 \mathrm{~F} \mathrm{BGC}$. The relevant artery is catheterized using the $5 \mathrm{~F}$ angiocatheter and the external carotid artery navigated using a 0.035 -inch wire (a stiff wire, if needed). The $5 \mathrm{~F}$ angiocatheter is then advanced over the 0.035 -inch wire, followed by the $\mathrm{BGC}$. In rare instances, a triple coaxial technique, a $5 \mathrm{~F}$ long (125-cm length) angiocatheter within a 100-115-cm length $6 \mathrm{~F}$ catheter (Envoy or intermediate catheter group) within a $9 \mathrm{~F}$ $B G C$, is needed to overcome the challenges of very tortuous anatomy or ledge effects at the origin of the common carotid artery. $^{14}$

Another option for the guiding system is a combination of a $6 \mathrm{~F}$ or $7 \mathrm{~F}$ Shuttle guide catheter plus an intermediate $5 \mathrm{~F}$ or $6 \mathrm{~F}$ catheter. When this combination is used, the intermediate catheter must be advanced as close as possible to the target occlusion site. It would be better to go well above than below the ophthalmic curve of the internal carotid artery (ICA), which would likely arrest downstream blood flow during the retrieval of the SR. One advantage of this combination is that sequential or simultaneous thrombectomies are possible using an SR and an intermediate catheter.

For cases in which the relevant ICA is very tortuous, determining the optimal combination has been controversial. The combination of BGC $9 \mathrm{~F}+6 \mathrm{~F}$ intermediate catheter or the $8 \mathrm{~F}$ $B G C+5 F$ intermediate catheter coaxial system both work well and the operator can proceed according to his or her preference. Depending on the amount of clots and the tortuosity of the vascular tree, it is also possible to apply a triple coaxial combination of an $8 \mathrm{~F}$ shuttle+8 $\mathrm{F} \mathrm{BGC}+5 \mathrm{~F}$ intermediate catheter. $^{14}$

\section{Microcatheter navigation and SR deployment}

A 4-mm diameter SR is compatible with a microcatheter with a 0.0195-inch or 0.021-inch inner diameter. Thus, any type of microcatheter (Excelsior 1018, Stryker, Fremont, CA, USA; Rebar-18, Medtronic, Irvine, CA, USA; Prowler plus, Coddman, Ratham, MA, USA) with a $\geq 0.0195$-inch inner diameter can be used at the operator's discretion. However, when using a 5-mm or 6-mm diameter SR, a microcatheter with a 0.027-inch inner diameter is required. The microcatheter is navigated beyond the occluded point of the relevant intracranial artery using a 0.014inch microwire. Thereafter, a small amount of contrast material is infused to confirm that the microcatheter has been correctly positioned in the main branch of the occluded parent artery. A manual microcatheter angiogram should be avoided because it may be potentially dangerous in the segment that has been closed both proximally and distally due to clots. An appropriatesized SR is then introduced and deployed to span the entire length of the occluded clot. In the earlier phase of SR implementation, the usual "push-and-pull technique" was recommended. Recently, however, the "push and fluff technique" has proven superior for the successful removal of clots. ${ }^{14,18}$ After positioning the distal tip marker of the SR, instead of unsheathing the microcatheter, the SR is deployed by pushing the delivery wire; this process is referred to as the "push and fluff" technique. This technique leads to a better wall apposition of the SR and cell size/configuration, which in turn promotes better engagement of the clot with the SR and increases the likelihood of first-pass recanalization. ${ }^{14,18}$ Pushing of the delivery wire should be done only after confirming that distal marker of the SR is well expanded in order to avoid vessel injury by moving the SR. A control angiogram is generally obtained immediately after deploying the SR to confirm the accuracy of the SR position and restoration of the blood flow beyond the initial occlusion site. An additional control angiogram is typically obtained after waiting 3-5 minutes, at the operator's discretion.

\section{Retrieval of the SR}

The BGC balloon is inflated, which appears cylindrical. During the simultaneous retrieval of the SR and the microcatheter, the BGC needs to be continuously suctioned with a 20-50-mL syringe to prevent any distal embolization. After retrieving the $S R$, the BGC still needs to be continuously suctioned until clear blood without any clot debris is aspirated. Finally, the BGC is deflated and a routine angiogram is obtained. ${ }^{14}$

\section{Complicated Situations in EVT}

\section{Tandem occlusions of cervical artery and intracranial artery}

Cervical carotid artery atherosclerotic disease is responsible for $15-30 \%$ cases of acute stroke, of which the majority are due to an artery-to-artery embolism with occlusion or severe stenosis. If the cervical carotid artery or vertebral artery disease causes tandem cervical and intracranial artery occlusions, which is 
usually the case, it is unclear whether to first treat the intracranial artery occlusion or the cervical artery occlusion. However, in the SR thrombectomy era, neurointerventionalists seem to favor opening the cervical artery occlusion first, followed by a SR thrombectomy for the tandem intracranial artery occlusion, as the cervical artery must be sufficiently dilated when using an SR. ${ }^{14,19-25}$ Another reason for treating cervical artery disease is that a tandem intracranial occlusion can spontaneously dissolve after sufficient dilatation of the cervical ICA..$^{20,26}$ Finally, timely recanalization of the cervical ICA not only improves the collateral flow to the ischemic penumbra, but also augments the regional perfusion pressure and delivers fresh blood to the intracranial occlusion site to facilitate endogenous thrombolysis, thereby leading to the possibility of delayed recanalization after finishing the procedure, even in the case of a failed intracranial thrombectomy. ${ }^{14,26-28}$

The procedural details are as follows (Figure 1):

1. An $8 \mathrm{~F} / 9 \mathrm{~F} \mathrm{BGC}$ is placed proximal to the occluded or severely stenosed carotid artery using a coaxial technique, as described previously. When a BGC is chosen, a $9 \mathrm{FBGC}$ is preferred over an $8 \mathrm{FBGC}$, as the inner lumen of the BGC should be $\geq 6 \mathrm{~F}$ to facilitate insertion of various sizes of carotid stents.
2. The BGC balloon is inflated and the cervical segment of the ICA is accessed using a 0.014-inch microwire beyond the occlusion. If the passing of a microwire is prolonged due to anatomical difficulty, the BGC balloon may be inflated after the microwire pass to prevent clot formation during the balloon inflation. A 4-5-mm-diameter balloon is then advanced over the wire. If access to the occluded segment is difficult with just the microwire, an exchange technique using a microcatheter and a 300-cm length exchangeable microwire can be utilized before introducing the angioplasty balloon.

3. Following the angioplasty for an occluded cervical carotid artery, the BGC should be suctioned to aspirate any debris before deflation.

4. Depending on the patient's medical status and cross-collaterals via communicating arteries, an SR thrombectomy for a tandem intracranial occlusion can be performed first. After recanalization of the intracranial artery, CAS may be done in the same session or later, after discussion with an attending physician. Another option is to perform the carotid artery stenting first, followed by an SR thrombectomy. ${ }^{14}$

5. If the carotid stenting is performed first, the BGC is ad-
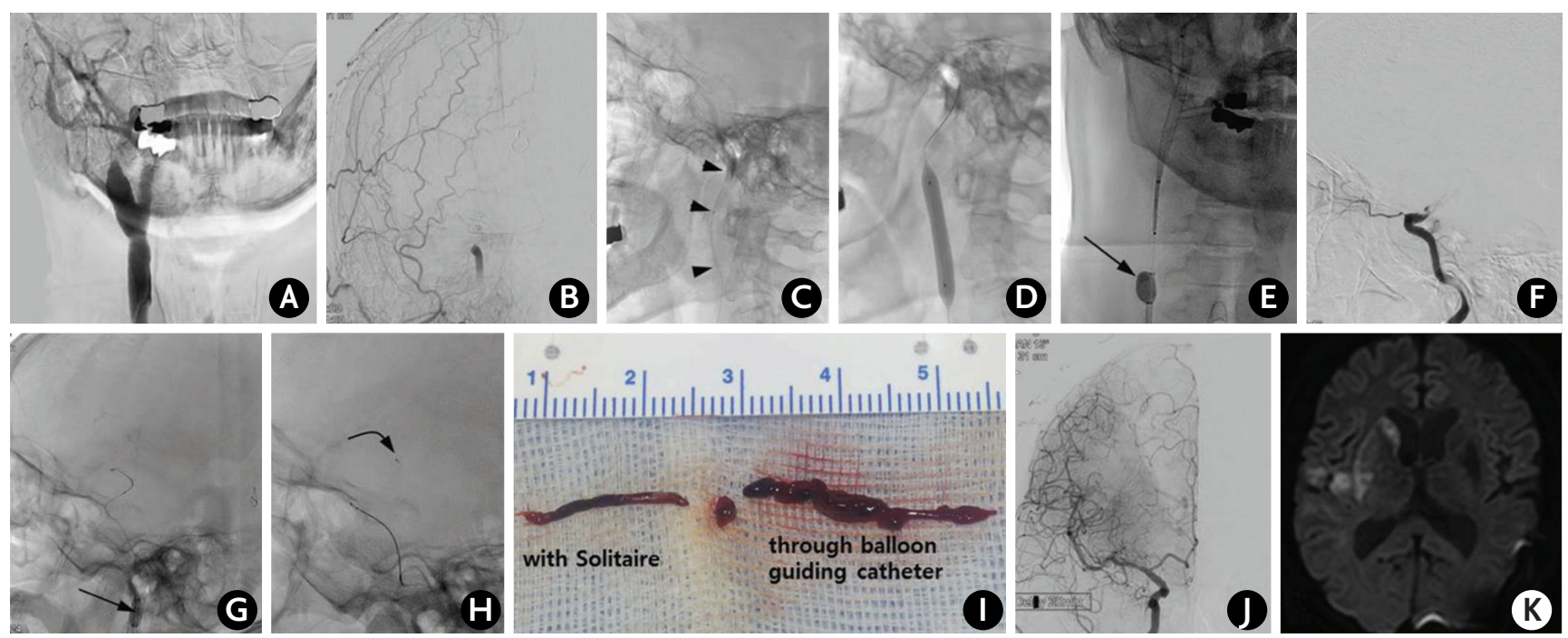

Figure 1. A 60-year-old man presented with left side weakness (initial NIHSS score of 15). (A) A right carotid angiogram revealed occlusion of right internal carotid artery at the proximal cervical segment. (B) The delayed phase of the angiogram disclosed tandem occlusion of the right internal carotid artery at the supraclinoid segment. (C) After a balloon-guiding catheter was placed in the common carotid artery, the internal carotid artery was navigated using a microcatheter (arrowheads). (D) After an angioplasty balloon catheter was advanced over the 300-cm length exchangeable microwire, a balloon angioplasty was performed. (E) A closed-cell carotid stent was placed while the distal tip of the balloon of the guiding catheter was inflated (arrow). (F) A balloon-guiding catheter was advanced to the end of the carotid stent. Thereafter, the angiogram shows a tandem occlusion of the supraclinoid internal carotid artery. (G) A microcatheter was navigated into the middle cerebral artery branch during balloon inflation (arrow). (H) A Solitaire stent retriever was deployed spanning the entire clot length. A curved arrow indicates a distal marker of the deployed Solitaire. Arrow indicates inflated balloon guide catheter. (I) A large amount of clots was removed with the Solitaire through the balloon-guiding catheter suction. (J) Control angiogram revealed complete (modified Thrombolysis in Cerebral Ischemia $[\mathrm{mTICl}] 3$ ) recanalization. (K) Diffusion-weighted magnetic resonance imaging on the following day showed small areas of acute infarctions in the right middle cerebral artery territory. NIHSS, the National Institutes of Health Stroke Scale. 

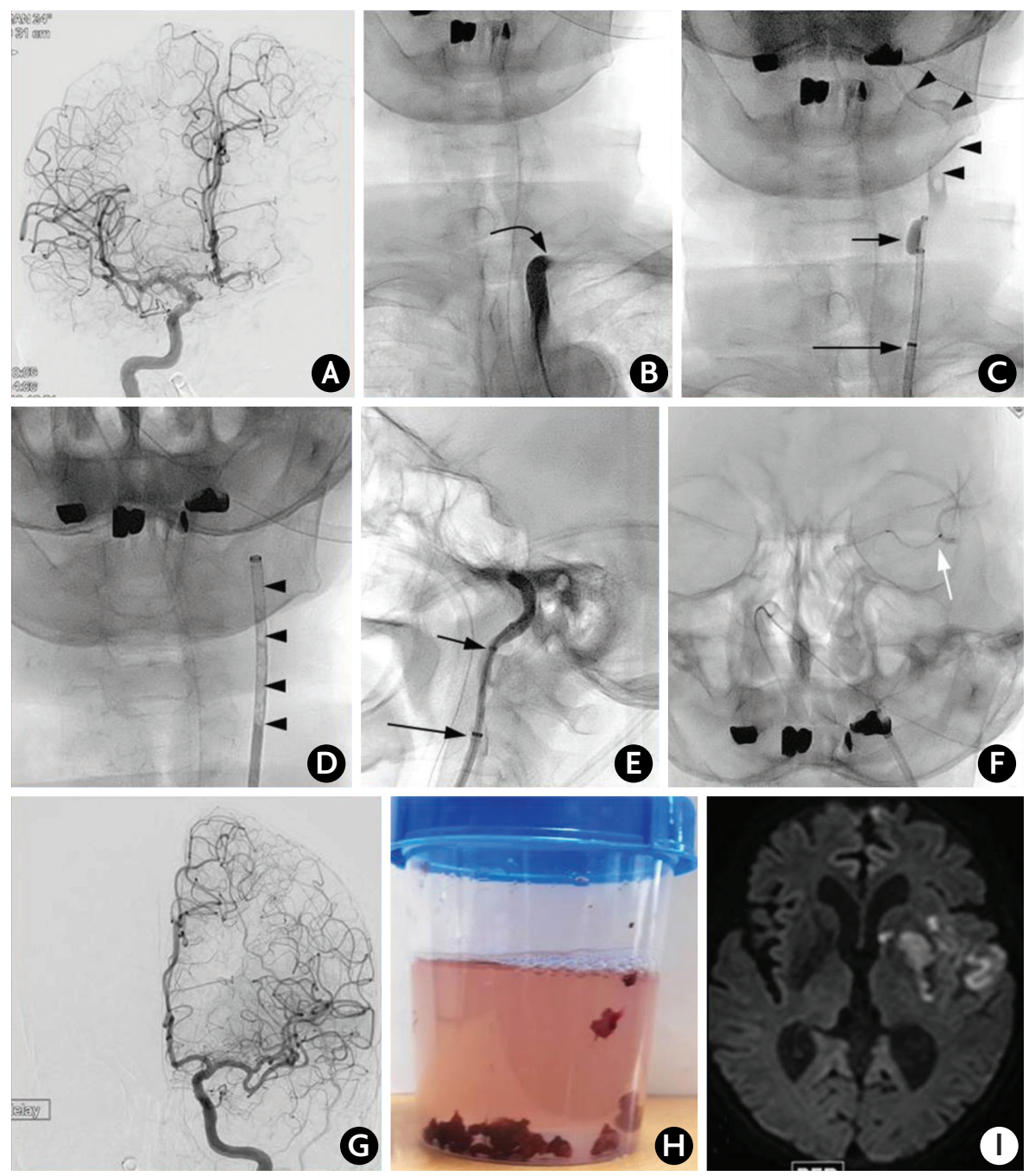

Figure 2. A 74-year-old woman presented with mental changes and right side weakness (initial NIHSS score of 18). (A) A right carotid angiogram showed left internal carotid artery terminal occlusion. (B) A spot image during the navigation of an angiocatheter disclosed the left common carotid artery at the proximal occlusion (curved arrow). (C) After suction of a large quantity of clots through the $8 \mathrm{~F}$ shuttle sheath (long arrow), an $8 \mathrm{~F}$ balloonguiding catheter was advanced up to the carotid bulb (short arrow). Another suction was performed through the balloon-guiding catheter after inflation of the tip of the balloon. Note the large quantity of clots (filling defects, arrowheads). (D) After removal of the balloon-guiding catheter because it was occluded with packed clots, the shuttle sheath was also found to be occluded with clots (arrowheads). (E) After forced suction through shuttle sheath, an angiogram revealed occlusion of an internal carotid artery cavernous segment. The balloon-guiding catheter (short arrow) was reintroduced within a shuttle sheath (long arrow) and advanced up to a high cervical segment. (F) The left middle cerebral artery main branch was navigated using a microcatheter (white arrow). (G) After a Solitaire stent retriever was passed once, the control angiogram showed complete recanalization. (H) A large number of clots in the bottle. Most of the clots were removed through suction of the shuttle sheath and the balloonguiding catheter. (I) Diffusion-weighted magnetic resonance imaging on the following day disclosed scattered acute infarctions in the left middle cerebral artery. NIHSS, the National Institutes of Health Stroke Scale. vanced to the distal end of the carotid stent to avoid the SR getting stuck on the struts of the placed carotid stent. For the same reason, a closed-cell-type carotid stent is preferred over an open-cell-type stent. ${ }^{14,20}$ Meanwhile, if the SR thrombectomy is performed first, the BGC is advanced beyond the pathologic segment of the cervical carotid artery over the deflated angioplasty balloon immediately following the angioplasty.

6. A control angiogram is obtained to confirm any remnant intracranial artery occlusion.

7. Thereafter, the steps are the same as for a standard SR thrombectomy for an intracranial artery occlusion.

\section{Huge clots in the ICA in addition to intracranial occlusion}

In the case of a large quantity of clots in the cervical artery concomitant with a tandem intracranial artery occlusion, it is not possible to remove all of the clots using just an SR. In that situation, it is more effective to first perform a suction thrombectomy using a BGC and/or large bore shuttle sheath before the SR thrombectomy. Since the BGC itself can be occluded by packed clots during the suction thrombectomy, a coaxial combination of an $8 \mathrm{~F} \mathrm{BGC}$ within an $8 \mathrm{~F}$ shuttle sheath is also needed, which, in the case of occlusion, allows the BGC to be deflated and retrieved outside the shuttle sheath while maintaining the negative suction of the BGC. Thereafter, the shuttle sheath left in the cervical artery needs continuous suctioning until clear blood is aspirated (Figure 2). Following the suction thrombectomy, an SR thrombectomy can be performed to remove any remnant distal clots. ${ }^{14}$

\section{Severe arterial tortuosity}

If the relevant parent artery is very tortuous or includes a stenotic segment proximal to the occlusion site, the probability of losing the SR-engaged clots increases. In addition, continuous suction of the BGC may not be sufficient to prevent distal em- 

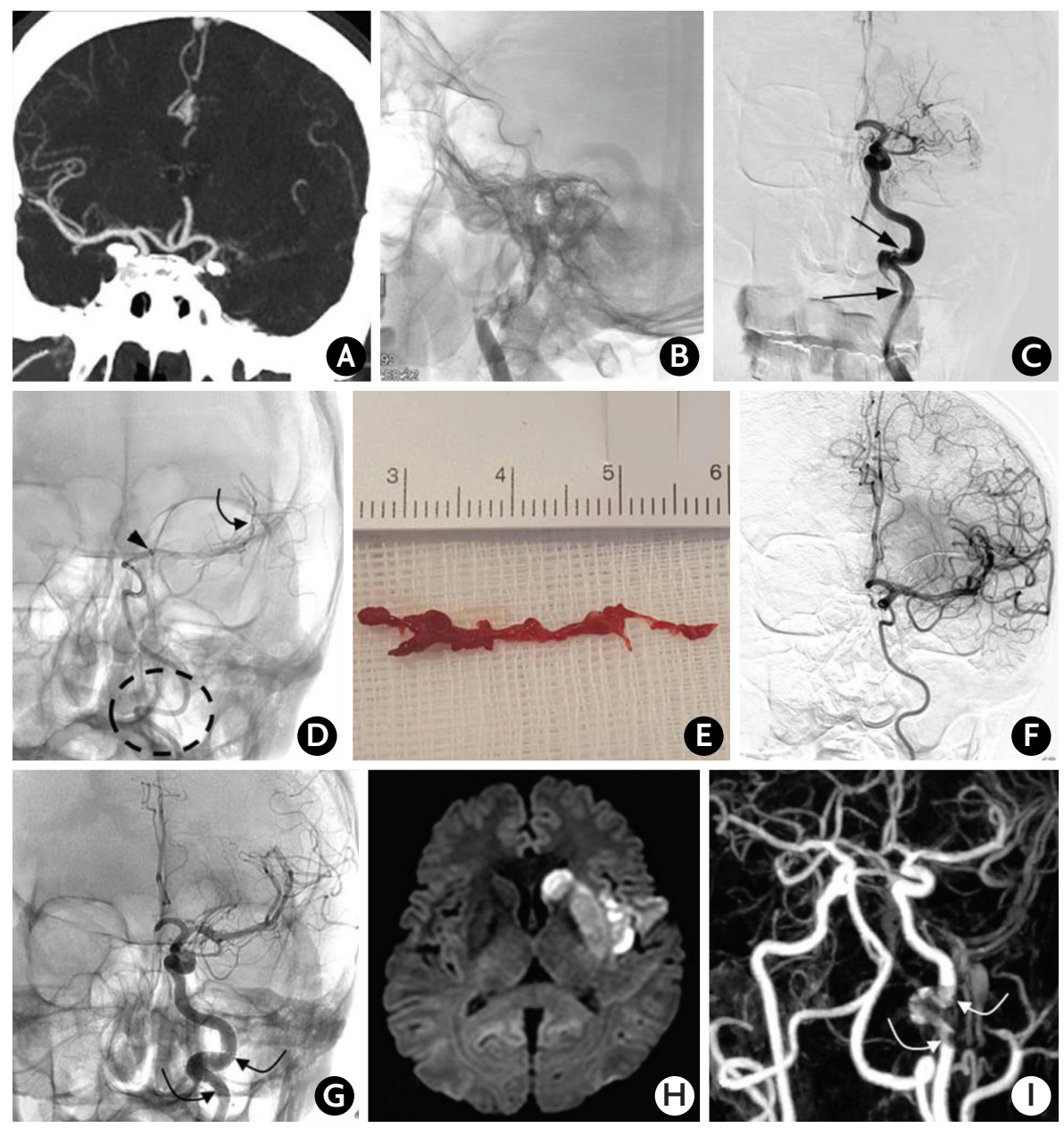

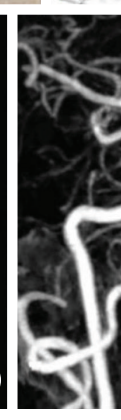

$\boldsymbol{F}$

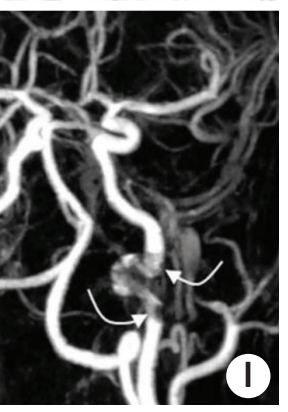

Figure 3. A 47-year-old man presented with aphasia and right side weakness (initial NIHSS score of 21). (A) An initial computed tomography angiogram showed occlusion of the left middle cerebral artery orifice. (B) A spot image during the navigation of a balloon-guiding catheter showed an occlusion of the high cervical portion of the internal carotid artery. (C) After a single suction thrombectomy through a balloon-guiding catheter, an angiogram showed a dissection (arrows) of the high cervical segment of the internal carotid artery with a tandem occlusion in the middle of the cerebral artery orifice. (D) For bypass of the tortuous and dissected segment of the internal carotid artery (dotted circle), a 6F intermediate catheter (arrowhead) was advanced after deployment of a Solitaire $(4 \times 20 \mathrm{~mm})$, which served as an anchor during the advancement of the intermediate catheter. A curved arrow indicates the distal markers of the Solitaire stent retriever. (E) A long clot retrieved with the Solitaire. (F) A control angiogram showed complete recanalization of the left middle cerebral artery. (G) Another Solitaire stent $(6 \times 30 \mathrm{~mm})$ was placed and detached, spanning the dissected segment (curved arrows) of the internal carotid artery. (H) Diffusion-weighted magnetic resonance imaging on the following day showed acute infarction in the left basal ganglia, insula, and opercular portion. (I) A contrast-enhanced magnetic resonance angiogram showed a patent left internal carotid artery through the stented segment (curved arrows). NIHSS, the National Institutes of Health Stroke Scale. bolization. In this case, the coaxial use of a $5 \mathrm{~F}$ (compatible with an 8 F BGC) or a 6 F intermediate (compatible with a 9 F BGC) may help increase the likelihood of complete clot retrieval. An intermediate catheter is coaxially introduced through the BGC and advanced as close as possible to the SR-engaged clots. In the event that it is difficult to advance the intermediate catheter close enough to the clot, SR is first deployed spanning the clot, which serves as an anchor during the intermediate catheter advancement (Figure 3). This combination of an SR and an intermediate catheter helps to prevent the engaged clots from being lost upon retraction of the SR back through the tortuous or stenotic segment of the relevant arterial tree. It can be also useful to facilitate the sequential or simultaneous performance of a combined technique of an SR and aspiration thrombectomy (Figure 4). ${ }^{14}$

\section{Refractory Occlusion to Mechanical Thrombectomy}

The pathomechanism (embolic versus non-embolic) of an acute LAO or the physical properties of the clot (soft versus hard/organized) can play a key role in the response to an SR. In addition, certain complications, such as inadvertent detachment, the SR getting stuck and repeated re-occlusion, have also been reported in relation to the pathomechanism of acute LAO. ${ }^{29-34}$ Finally, in this review, the probable causes of refractoriness to an SR will be discussed along with potential solutions.

\section{For underlying intracranial artery stenosis}

In Asian populations, intracranial atherosclerotic stenosis (ICAS) is one of the major causes of acute stroke, with recent studies showing that ICAS is responsible for $15-20 \%$ of acute LAO strokes. ${ }^{29,31-34}$ The majority of non-embolic occlusions are truncaltype occlusions (TT), as revealed in angiograms during intra-arterial recanalization treatment, and most are due to ICAS thrombo-occlusion (Figure 5). ${ }^{29,30}$ TOS tend to show refractoriness to an SR due to repeated re-occlusion. ${ }^{29-36}$ The application of an SR can damage the atheromatous surface if an acute LAO is due to ICAS thrombo-occlusion. In this case, the use of an SR can result in further platelet activation, leading to repeated re-occlusion 

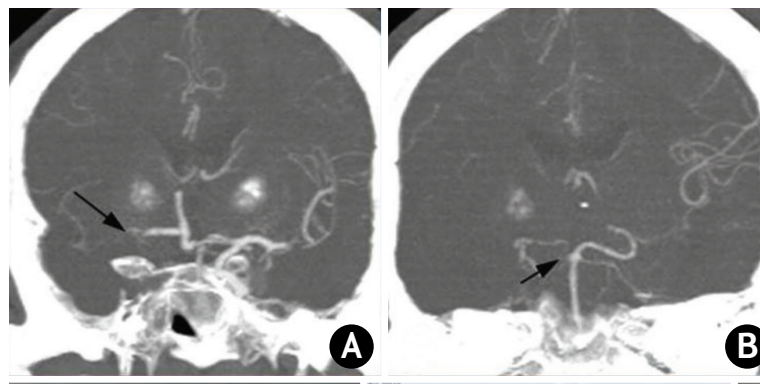

B.
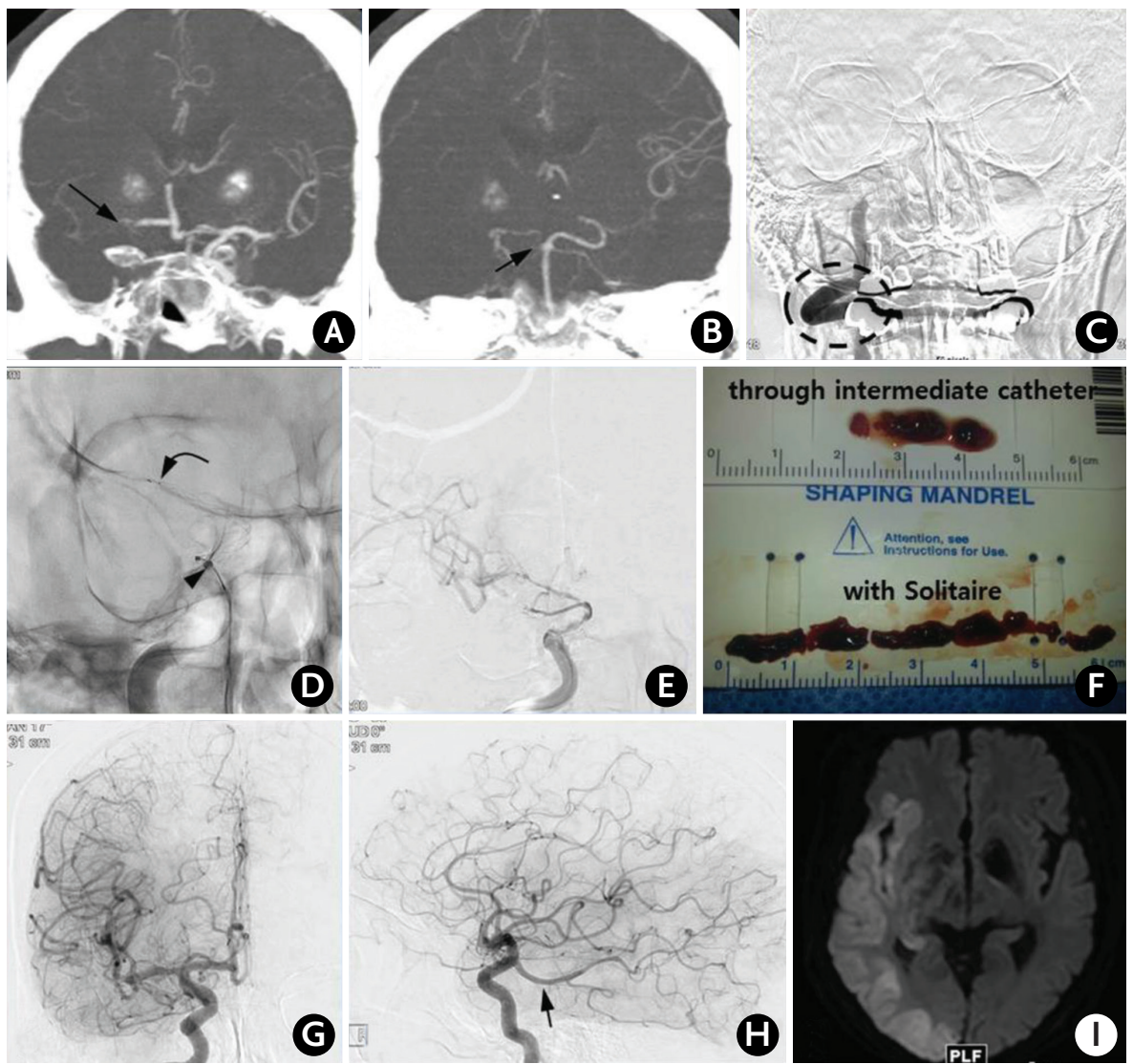

\section{जo}

G

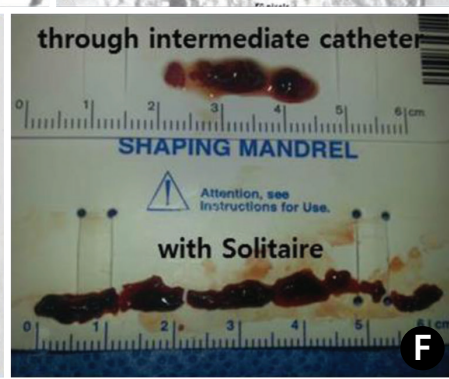

E
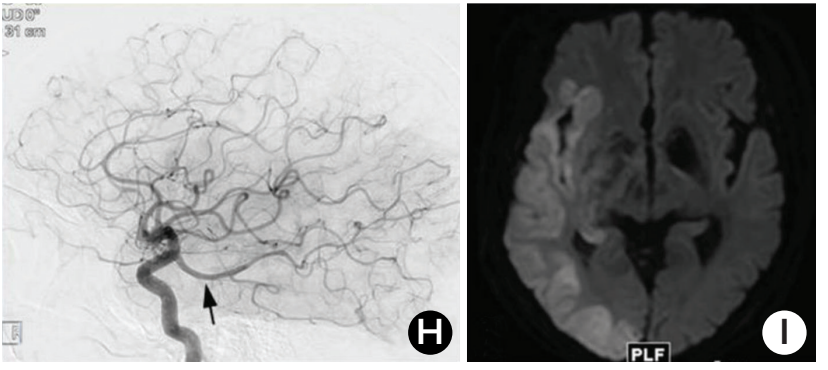

Figure 4. A 65-year-old woman presented with left side weakness (initial NIHSS score of 17). (A) A computed tomography angiogram showed an occlusion of the right internal carotid artery terminal portion (long arrow). (B) On the same computed tomography angiogram, take-off of the right posterior cerebral artery from the basilar artery was not visualized (short arrow), suggestive of a fetal-type posterior cerebral artery arising from internal carotid artery. (C) A right carotid angiogram showed an occlusion of the right internal carotid artery petro-cavernous segment. Note the tortuosity of the cervical segment (dotted circle) of the internal carotid artery. (D) After deployment of a Solitaire, a $6 \mathrm{~F}$ intermediate catheter (arrowhead) was advanced facing the clots. A curved arrow indicates the distal markers of the deployed Solitaire. (E) A 3-minute delay angiogram showed long clots from the cavernous segment of the internal carotid artery to the middle cerebral artery. (F) A large quantity of clots was removed with the Solitaire and through the intermediate catheter. $(\mathrm{G}$, H) An anteroposterior and lateral control angiogram showed complete recanalization. Note the fetal-type posterior cerebral artery (short arrow) originating from the internal carotid artery. (I) Diffusion-weight magnetic resonance imaging on the following day showed a large area of cortical infarction along the middle cerebral and posterior cerebral artery areas. NIHSS, the National Institutes of Health Stroke Scale.

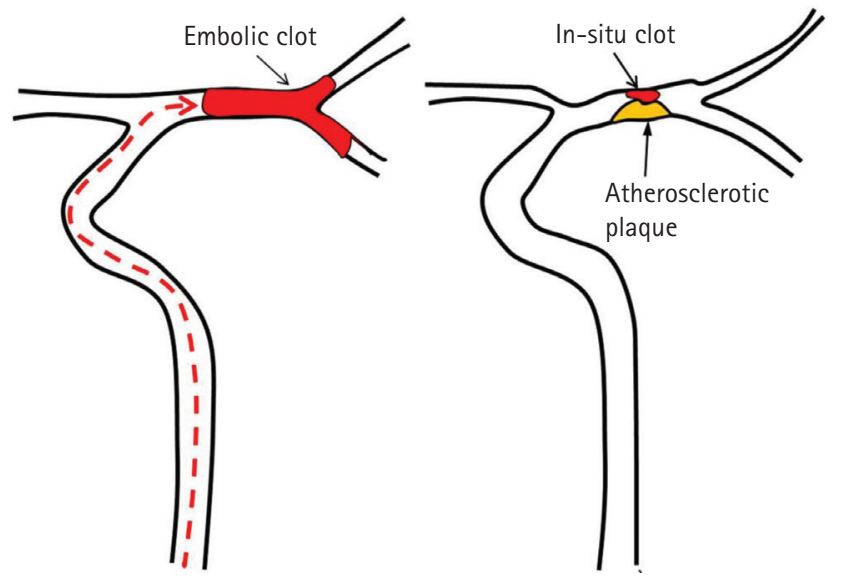

Figure 5. A schematic comparing a branching-site (embolic, left) occlusion and a truncal-type (nonembolic, right) occlusion.

(Figure 6) ${ }^{29-36}$ To prevent repeated re-occlusion in the case of an LAO due to ICAS, inhibition of the platelet function can play a key role. Therefore, the first option is to administer a glycoprotein Ilb/Illa inhibitor, which inactivates platelets and thereby prevents repeated re-occlusion. ${ }^{29,31,36-38}$ However, ICAS occlusions are oc- casionally refractory to glycoprotein IIb/IIla inhibitors. For recanalization in such a case, permanent stenting with or without balloon angioplasty can be applied (Figure 6). ${ }^{29,31,32}$

\section{For hard organized clots}

An organized (hard, fibrin-rich) clot is more resilient and less sticky than fresh (soft, red blood cell-rich) clots, causing less engagement with an SR and leading to clot missing during SR retrieval, especially in the case of a tortuous arterial tree. Furthermore, because an organized clot may cause more tension in the SR-deployed segment of the parent artery, this can also likely induce an arterial spasm. Such effects then increase the probability of SR failure. ${ }^{29}$

For successful recanalization of an LAO due to an organized clot, the first and simplest option is the intra-arterial administration of a vasodilator, which releases the tension of the SR deployed arterial segment, thereby increasing the vessel diameter to ease clot retrieval (Figure 7). ${ }^{29}$ The second option is the simultaneous utilization of an SR and an aspiration or intermediate catheter. After deploying the SR, an aspiration catheter or intermediate catheter is advanced as close to the clot as possi- 

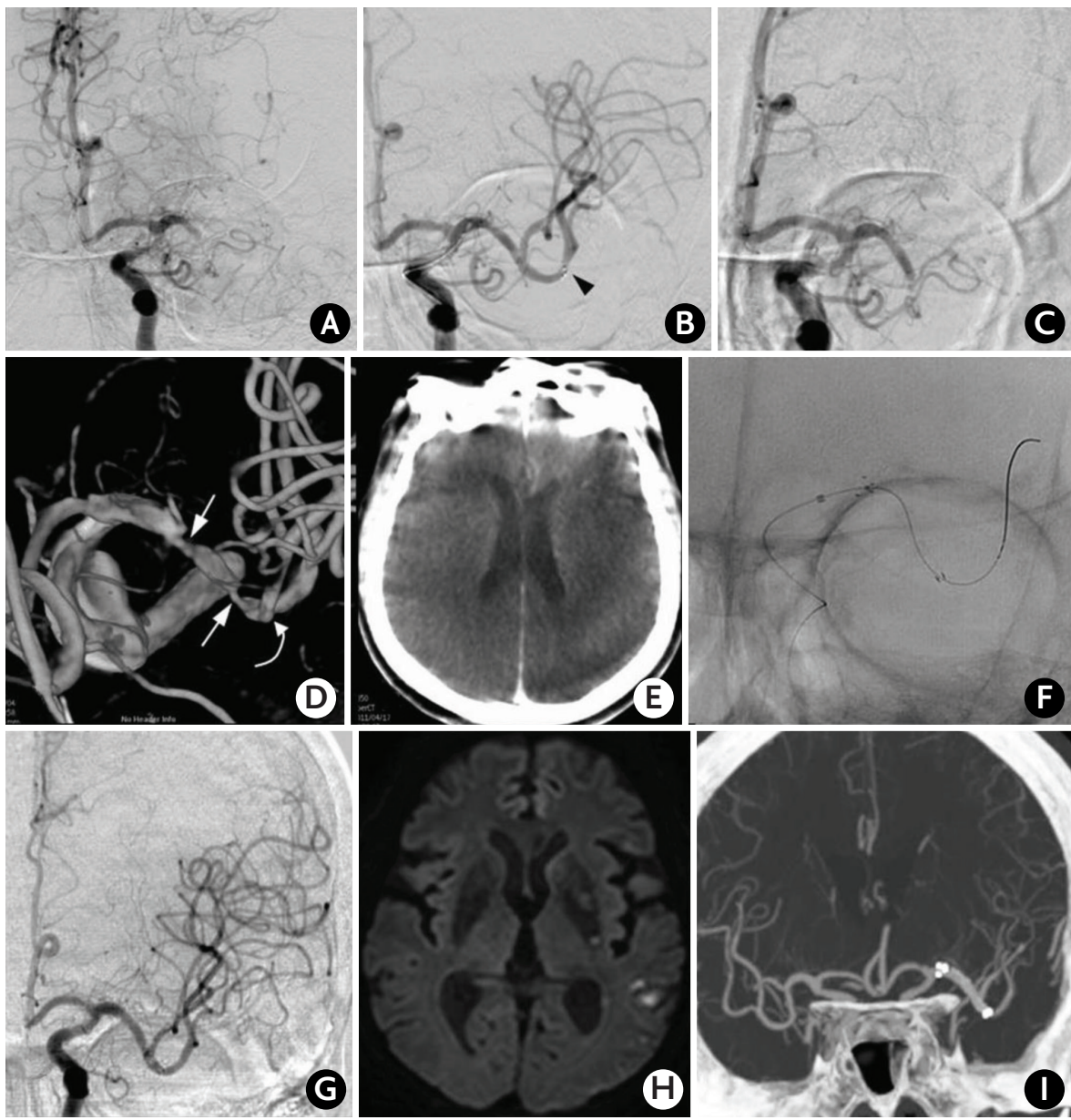

Figure 6. A 67-year-old man presented with aphasia and right side weakness (initial NIHSS score of 13). (A) A left carotid angiogram showed left middle cerebral artery M1 occlusion. (B) A control angiogram just after a Solitaire deployment showed complete recanalization. An arrowhead indicates the distal markers of the Solitaire. (C) An angiogram after retrieval of the Solitaire showed re-occlusion. This phenomenon of complete recanalization after the Solitaire placement and re-occlusion after the retrieval was repeated 5 times. (D) A 3D volume-rendering reconstruction image obtained during the Solitaire deployment showed 2 spots of stenosis (white arrows). Note the bifurcation (curved arrow) of the middle cerebral artery that was saved. (E) A flat-panel angiographic computed tomography showed minimal contrast agent enhancement in the left middle cerebral artery territory. A glycoprotein Ilb/Illa inhibitor was intra-arterially administered through the microcatheter, but the occlusion showed no response. (F) A Wingspan stent was placed after the balloon angioplasty. (G) The final control angiogram after permanent stenting showed complete recanalization. (H) Diffusionweighted magnetic resonance imaging on the following day showed several small high signal spots in the left middle cerebral artery area. (I) A 3-month follow-up computed tomography angiogram showed that the stented segment of the left middle cerebral artery was patent. NIHSS, the National Institutes of Health Stroke Scale.
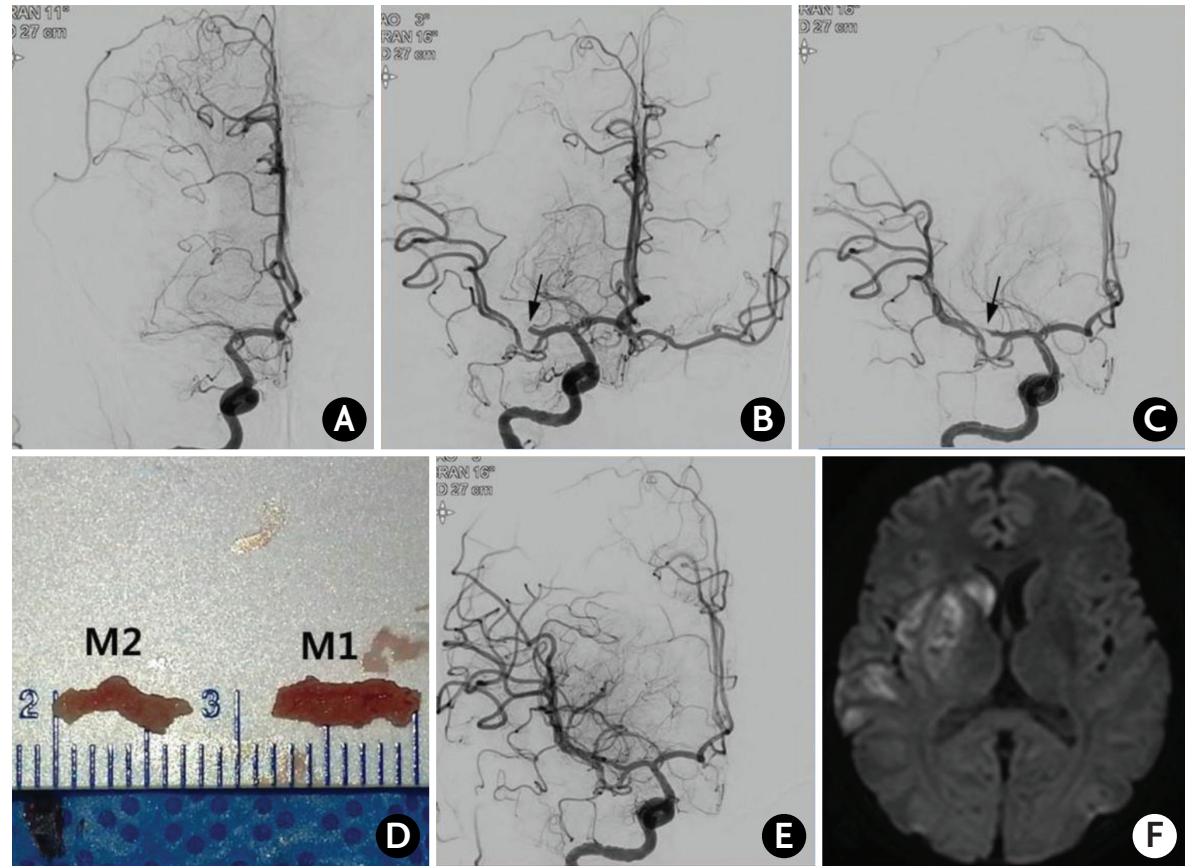

Figure 7. A 58-year-old woman presented with left side weakness (initial NIHSS score of 14). (A) A right carotid angiogram showed an occlusion of the right middle cerebral artery orifice. (B) After a single Solitaire pass, the M1 segment and inferior division (arrow) were recanalized, but the superior division was still occluded. (C) After 2 more Solitaire passes, the superior division was still occluded and showed a spastic appearance. A $4^{\text {th }}$ Solitaire pass was performed after intra-arterial vasodilator (nimodipin, 0.5 $\mathrm{mg}$ ) infusion (arrow) through the microcatheter while the Solitaire was deployed. (D) Two organized clots from M1 and M2 (superior division). (E) The control angiogram after the $4^{\text {th }}$ pass of the Solitaire showed complete recanalization of the middle cerebral artery. (F) Diffusion-weighted magnetic resonance imaging on the following day showed small areas of acute infarction in the right middle cerebral artery territory. NIHSS, the National Institutes of Health Stroke Scale. 

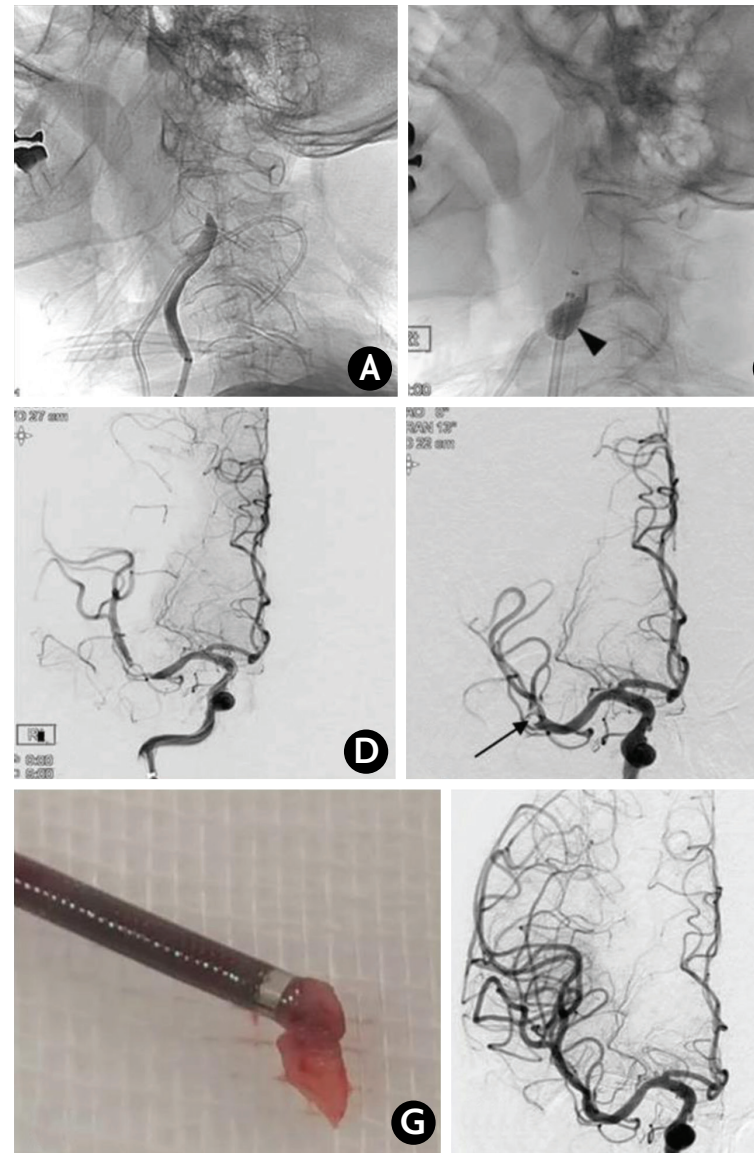

E
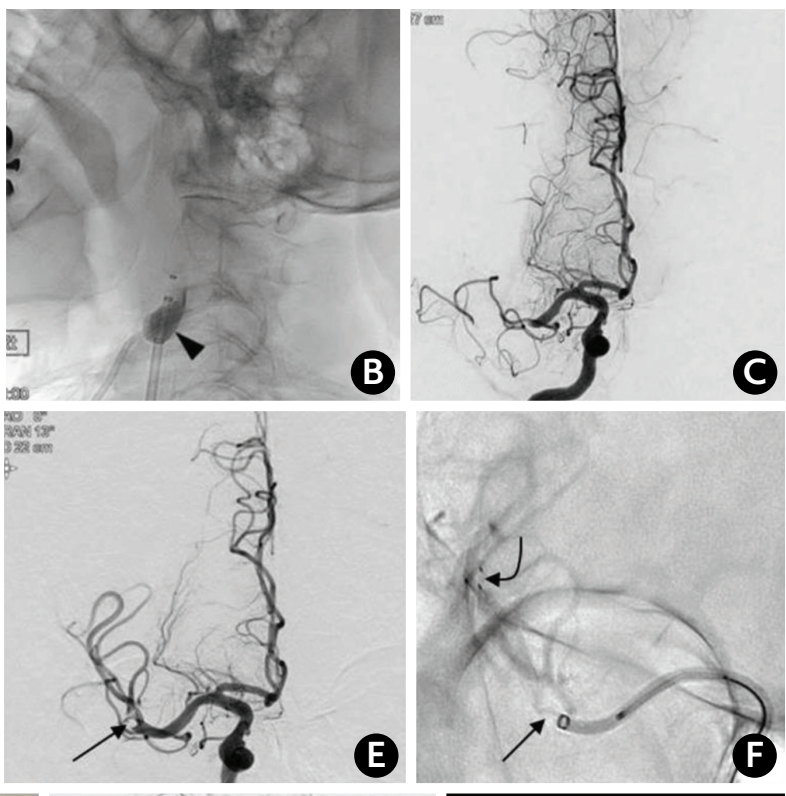

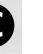

(E) In spite of repeated Solitaire passes, one clot (filling defect, arrow) was not removed. (F) A $5 \mathrm{~F}$ intermediate catheter was advanced facing the clot (arrow) after anchoring the Solitaire (curved arrow). (G) The Solitaire retrieval yielded nothing, but the organized clot was captured by the intermediate catheter. $(\mathrm{H})$ The final control angiogram showed complete recanalization. (I) Diffusion-weighted magnetic resonance imaging on the following day showed two high signal spots in the right middle cerebral artery territory. NIHSS, the National Institutes of Health Stroke Scale.

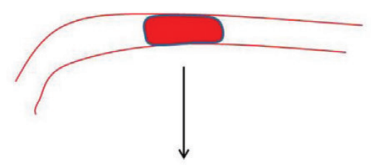

Just after deployment of stent retriever

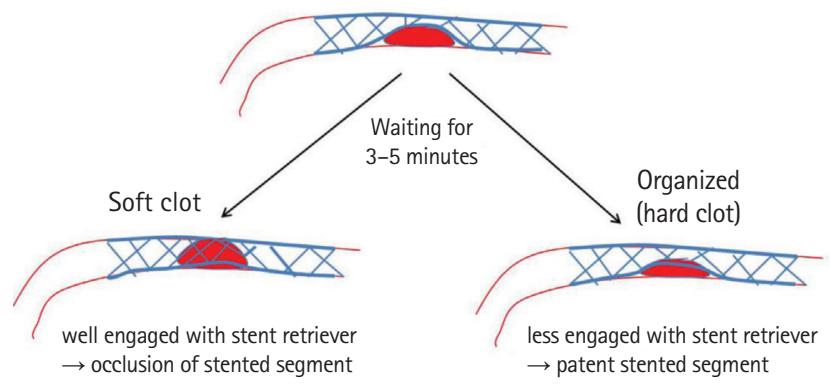

Figure 9. Schematic drawings show interactions of the stent with soft (red blood cell-rich) clots or organized (fibrin-rich) clots.

ble. An SR and suction thrombectomy can be performed sequentially or simultaneously (Figure 8 ). ${ }^{29}$

If the organized clot is still refractory after the simultaneous utilization of an SR and an intermediate catheter, permanent stenting can be considered as a final resort.29,32 The organized clot may be refractory due to less engagement with the SR. ${ }^{29,39}$ By the same token, if permanent stenting is conducted, the stented artery is likely more patent as the organized clot is less engaged inside the stent struts (Figure 9). 29,32

\section{Permanent stenting for LAO refractory to mechanical thrombectomy}

Irrespective of the etiology of the refractoriness of an LAO, a rescue modality is needed for such a refractory case given that successful recanalization is the most powerful factor for a good outcome. ${ }^{6,31,40}$ One possible modality is the intra-arterial infusion of thrombolytics (tissue plasminogen activators or urokinase) and/or anti-platelets (glycoprotein Ilb/Illa inhibitors), which can promote $\mathrm{mTICl}$ 2b-3 recanalization in some refractory LA0s. ${ }^{29,31,32,36-38}$ For cases that are still refractory to the combination of an SR and an aspiration thrombectomy, as well as to intra-arterial infusion of thrombolytics and/or a glycoprotein Ilb/Illa inhibitor, the final rescue modality is permanent stenting, which has also been suggested both as a primary approach and a rescue tool for the recanalization of an acute $L A 0 .^{29,31,32,41-47} \mathrm{An}$ SR-failed LAO is likely due to either ICAS (Figure 5) or an organized (hard) clot (Figure 9), as previously discussed. In the case 

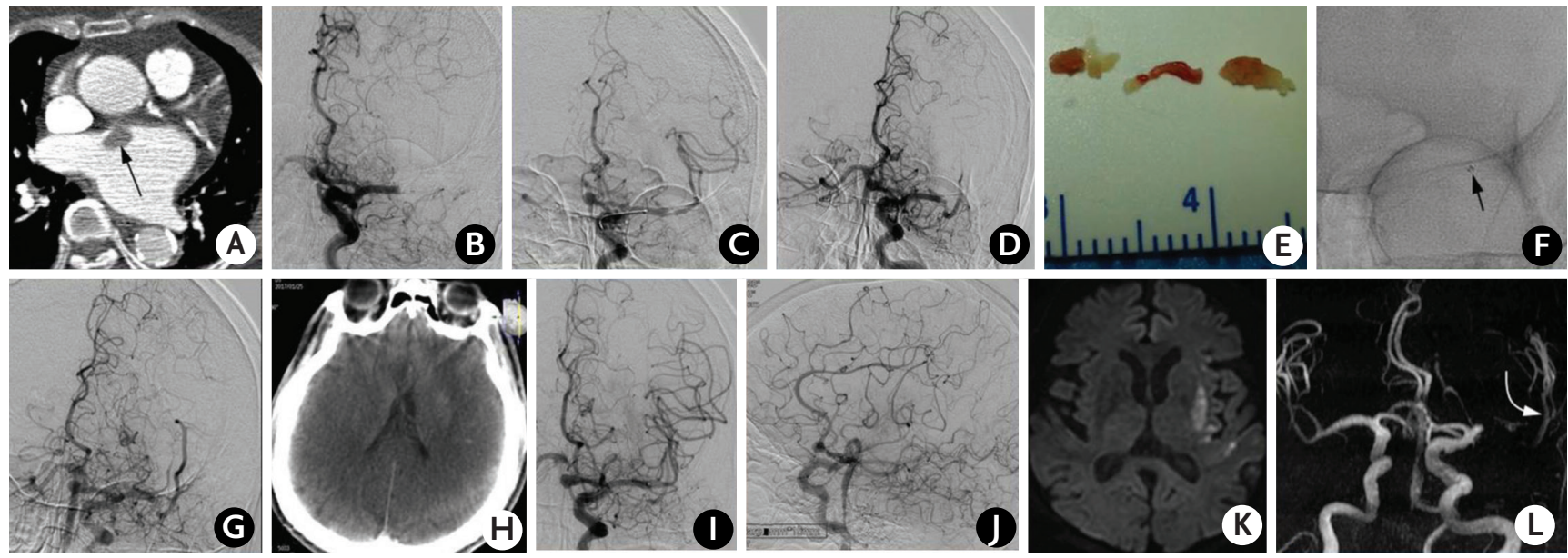

Figure 10. A 72-year-old woman presented with aphasia and right side weakness (initial NIHSS score of 19). (A) The lowest maximum intensity projection reconstruction image from a cerebral computed tomography angiogram showed a pedunculated thrombus in the left atrium. (B) A left carotid angiogram showed left middle cerebral artery M1 occlusion. (C) An angiogram with Solitaire in situ showed partial recanalization. (D) An angiogram after 5 passes of the Solitaire showed partial recanalization of the anterior temporal artery. (E) The clots were removed after 5 passes of the Solitaire. Note that the clots are resilient rather than sticky, suggestive of organized clots. (F) Suction thrombectomy was attempted using a Penumbra catheter (arrow). (G) An angiogram after 3 suction thrombectomy passes still showed occlusion in the middle cerebral artery beyond the orifice of the anterior temporal artery. (H) A flat-panel angiographic computed tomography showed minimal contrast agent enhancement in the left middle cerebral artery territory. Thereafter, a glycoprotein Illb/Illa inhibitor was administered, but the occlusion showed no response. (I) A 30-minute delay angiogram showed a patent left middle cerebral artery while the Solitaire was deployed but not detached. (J) The same angiogram showed at least modified $\mathrm{TICl} 2 \mathrm{~b}$ recanalization. Therefore, the Solitaire stent was detached. (K) Diffusion-weighted magnetic imaging on the following day showed scattered small infarctions in the left middle cerebral artery territory. (L) A magnetic resonance angiogram on the following day showed patent left middle cerebral artery branches (curved arrow). Note that the left middle cerebral artery trunk is not seen due to a metallic artifact of the stent. NIHSS, the National Institutes of Health Stroke Scale.

of an ICAS occlusion, the problem is mainly due to repeated occlusion. ${ }^{29,31-36,48}$ As mentioned above, a glycoprotein Ilb/Illa inhibitor can help prevent such reocclusion. Notwithstanding, ICAS occlusions are often refractory to glycoprotein IIb/IIla inhibitors, probably because of underlying severe stenosis. In such cases, permanent stenting combined with a glycoprotein IIb/IIla inhibitor can be very effective to recanalize. ${ }^{29,31,32,41-47}$ Permanent stenting can also be the last resort after the failure of an SR and aspiration thrombectomy due to an organized (hard, fibrinrich) clot (Figure 10). In a recently published study on the safety and efficacy of permanent stenting following a failed mechanical thrombectomy, 83.3\% of stented patients showed thrombolysis with a cerebral ischemia $2 b$ or 3 recanalization rate. The stented patients had significantly more favorable outcomes (modified Rankin Scale score [mRS] of 0-2, 35.5\%) and less cerebral herniation $(11.8 \%)$ than did the non-stented patients (mRS, 7.1\%; cerebral herniation, 42.9\%), while there were no differences in the symptomatic intracranial hemorrhage and mortality rates between the patient groups (symptomatic hemorrhage and mortality, $11.8 \%$ and $23.9 \%$, respectively, in the stented group vs. $14.3 \%$ and $39.4 \%$, respectively, in the nonstented group). ${ }^{32}$ Among 17 stented cases, only 40\% underwent balloon angioplasty. A Wingspan stent was used in 7 cases, while a Solitaire stent, which is also used for thrombectomies, was used in 10 cases. ${ }^{32}$ These results suggest that most of the refractory occlusions were due to a soft-plaque ICAS or organized embolus, rather than a hard-plaque ICAS. ${ }^{32}$ In other words, the radial force of the Solitaire stent, whose radial force is weaker than a Wingspan which is approved for intracranial stenting, was enough to open the occlusion, and angioplasty was not always required in the case of a soft-plaque or hard embolus occlusion. Meanwhile, platelet inactivation by a glycoprotein Ilb/Illa inhibitor was found to be essential to prevent reocclusion due to acute in-stent thrombosis. ${ }^{29}$ While the major concern with permanent stenting is that it requires antiplatelet medication, thereby possibly increasing the risk of intracranial hemorrhage in an acute stroke setting, the results of previous studies suggest that the benefit of recanalization success by permanent stenting outweighs this drawback in patients with an SR-failed LAO that would be otherwise left non-recanalized. ${ }^{29,32,40-47}$

In order to avoid the potentially increased rate of intracranial hemorrhage and severity due to anti-platelet medication in an acute stroke setting, it may be beneficial to obtain a flat-panel computed tomography scan in the angio-suite prior to permanent stenting and the administration of a glycoprotein Ilb/Illa inhibitor. If contrast agent enhancement is extensive in the affected brain, the EVT procedure should be stopped. Contrast agent enhance- 
ment of the affected brain indicates not only complete infarction, but also the breakdown of the blood-brain barrier and potentially increased hemorrhagic risk. On the other hand, if the contrast agent enhancement is small and not intense, administration of a glycoprotein Ilb/IIla inhibitor with permanent stenting can serve as a final resort (Figures $6 \mathrm{E}$ and $10 \mathrm{H}$ ). ${ }^{29}$

\section{Summary}

In this review, solutions of stent retriever failure are suggested as follows; 1 ) in the tandem atherosclerotic cervical ICA and embolic intracranial artery occlusion, angioplasty with or without stenting followed by SR thrombectomy for remnant intracranial occlusion seemed safe and effective. 2) In the case that a large amount of clots exist from cervical to intracranial artery, suction thrombctomy using BGC or a large bore guide catheter followed by SR thrombectomy may be a solution. 3) For tortuous cervical and cavernous ICA, coaxial utilization of intermediate catheter and BGC is recommended. 4) In the case that repeat reocclusions occur due to ICAS, GP IIb/IIla inhibitor may be effective in a half of the cases. If the occlusion is also refractory to GP Ilb/Illa, permanent stenting may be considered. 5) If a hard (organized) clot is suspected as a cause of stent retriever refractoriness, simultaneous utilization of aspiration and stent retreiver thrombectomy may be helpful.

\section{References}

1. Berkhemer $O A$, Fransen $P S$, Beumer $D$, van den Berg $L A$, Lingsma $\mathrm{HF}$, Yoo $\mathrm{A}$, et al. $A$ randomized trial of intraarterial treatment for acute ischemic stroke. N Engl J Med 2015; 372:11-20.

2. Campbell BCV, Mitchell PJ, Kleinig TJ, Dewey HM, Churilov L, Yassi N, et al. Endovascular therapy for ischemic stroke with perfusion-imaging selection. N Engl J Med 2015;372:10091018.

3. Goyal M, Demchuk AM, Menon BK, Eesa M, Rempel JL, Thornton J, et al. Randomized assessment of rapid endovascular treatment of ischemic stroke. N Engl J Med 2015;372:10191030.

4. Jovin TG, Chamorro A, Cobo E, de Miguel MA, Molina CA, Rovira $A$, et al. Thrombectomy within 8 hours after symptom onset in ischemic stroke. N Eng/J Med 2015;372:2296-2306.

5. Saver JL, Goyal M, Bonafe A, Diener HC, Levy El, Pereira VM, et al. Stent-retriever therombectomy after intravenous t-PA vs. t-PA alone in stroke. N Eng/ J Med 2015;372:2285-2295.

6. Goyal M, Menon BK, va Zwam WH, Dippel DW, Mitchell PJ, Demchuk AM, et al. Endovascular thrombectomy after largevessel ischaemic stroke: a meta-analysis of individual patient data from five randomized trial. Lancet 2016;387:1723-1731.

7. Campbell BC, Donnan GA, Lees KR, Hacke W, Khatri P, Hill $M D$, et al. Endovascular stent thrombectomy: the new standard of care for large vessel ischaemic stroke. Lancet Neurol 2015;14:846-854.

8. Song $\mathrm{D}, \mathrm{Cho}$ AH. Previous and recent evidence of endovascular therapy in acute ischemic stroke. Neurointervention 2015; 10:51-59.

9. Hong KS, Ko SB, Lee JS, Yu KH, Rha JH. Endovascular recanalization therapy in acute stroke: update meta-analysis of randomized controlled trials. J Stroke 2015;17:268-281.

10. Powers WJ, Derdeyn CP, Biller J, Coffey CS, Hoh BL, Jauch EC, et al. 2015 American Heart Association/American Stroke Association focused update of the 2013 guidelines for the early management of patients with acute ischemic stroke regarding endovascular treatment: a guideline for healthcare professionals from the American Heart Association/American Stroke Association. Stroke 2015;46:3020-3035.

11. Hong KS, Ko SB, Yu KH, Jung C, Park SQ, Kim BM, et al. Update of the Korean clinical practice guidelines for endovascular recanalization therapy in patients with acute ischemic stroke. JStroke 2016;18:102-113.

12. Eesa M, Burns PA, Almekhlafi MA, Menon BK, Wong JH, Mitha $A$, et al. Mechanical thrombectomy with the solitaire stent: is there a learning curve in achieving rapid recanalization times? J Neurointrevent Surg 2014;6:649-651.

13. Campbell $B C$, Hill MD, Rubiera M, Menon BK, Demchuk $A$, Donnan GA, et al. Safety and efficacy of solitaire stent thrombectomy: individual patient data meta-analysis of randomized trials. Stroke 2016;47:798-806.

14. Kim BM. Stent retriever (Stentriever) thrombectomy for acute stroke. In: Park J. Acute Ischemic Stroke: medical, endovascular, and surgical techniques. 1st ed. Singapore: Springer, 2017;191-212.

15. Velasco A, Buerke B, Stracke CP, Berkemeyer S, Mosimann PJ, Schwindt $W$, et al. Comparison of a balloon guide catheter and a non-balloon guide catheter for mechanical thrombectomy. Radiology 2016;280:169-176.

16. Nguyen TN, Malisch T, Castonguay AC, Gupta $\mathrm{R}$, Sun $\mathrm{CH}_{\text {, }}$ Martin $\mathrm{CO}$, et al. Balloon guide catheter improves revascularization and clinical outcomes with the solitaire device: analysis of the North American solitaire acute stroke registry. Stroke 2014:45:141-145.

17. Chueh JY, Kühn AL, Puri AS, Wilson SD, Wakhloo AK, Gounis MJ. Reduction in distal emboli with proximal flow control during mechanical thrombectomy: a quantitative in vitro study. Stroke 2013;44:1396-1401.

18. Houssen DC, Rebello CR, Nogueira RG. Optimizing clot re- 
trieval in acute stroke: the push and fluff technique for closed-cell stent retrievers. Stroke 2015;46:2838-2842.

19. Papanagiotou P, Roth C, Walter S, Behnke S, Grunwald IQ, Viera J, et al. Carotid artery stenting in acute stroke. J Am Coll Cardiol 2011;58:2363-2369.

20. Yoon W, Kim BM, Kim DJ, Kim DI, Kim SK. Outcomes and prognostic factors after emergent carotid artery stenting for hyperacute stroke within 6 hours of symptom onset. Neurosurgery 2015;76:321-329.

21. Mpotsaris A, Bussemeyer M, Buchner $H$, Weber W. Clinical outcome of neurointerventional emergency treatment of extra- or intracranial tandem occlusions in acute major stroke: antegrade approach with wallstent and solitaire stent retriever. Clin Neuroradiol 2013;23:207-215.

22. Stampfl S, Ringleb PA, Möhlenbruch $M$, Hametner $C$, Herweh $C_{1}$ Pham $M$, et al. Emergency cervical internal carotid artery stenting in combination with intracranial thrombectomy in acute stroke. AJNR Am J Neuroradiol 2014;35:741-746.

23. Cohen JE, Gomori JM, Rajz G, Itshayek E, Eichel R, Leker RR. Extracranial carotid artery stenting followed by intracranial stent-based thrombectomy for acute tandem occlusive disease. J Neurointervent Surg 2015;7:412-417.

24. Behme D, Mpotsaris $A$, Zeyen $P$, Psycholgios MN, Kowoll $A_{1}$ Maurer $\mathrm{CJ}$, et al. Emergency stenting of the extracranial internal carotid artery in combination with anterior circulation thrombectomy in acute ischemic stroke: a retrospective multicenter study. AJNR Am J Neuroradio/ 2015;36:2340-2345.

25. Sivan-Hoffmann R, Gory B, Armoiry X, Goyal M, Riva R, Labeyrie $P E$, et al. Stent-retriever thrombectomy for acute anterior ischemic stroke with tandem occlusion: a systematic review and meta-analysis. Eur Radiol 2017;27:247-254.

26. Loh Y, Liebeskind DS, Shi ZS, Jahan R, Gonzalez NR, Tateshima $S$, et al. Partial recanalization of concomitant internal carotidmiddle cerebral arterial occlusions promotes distal recanalization of residual thrombus within $24 \mathrm{~h}$. J Neurointervent Surg 2011;3:38-42.

27. Sakharov DV, Rijken DC. The effect of flow on lysis of plasma clots in a plasma environment. Thromb Haemostat 2000; 83:469-474.

28. Stein CM, Brown N, Vaughan DE, Lang CC, Wood AJ. Regulation of local tissue-type plasminogen activator release by endothelium-dependent and endothelium-independent agonists in human vasculature. J Am Coll Cardiol 1998;32:117-122.

29. Kim BM. Refractory occlusion to stentriever thrombectomy: etiological considerations and suggested solutions. In: Park J. Acute Ischemic Stroke: medical, endovascular, and surgical techniques. 1st ed. Singapore: Springer, 2017;212-226.

30. Gascou G, Lobotesis K, Machi P, Maldonado I, Vendrell JF,

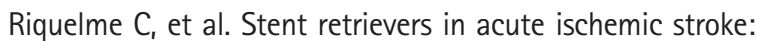
complications and failures during the perioperative period. AJNR Am J Neuroradiol 2014;35:734-740.

31. Baek JH, Kim BM, Kim DJ, Heo JH, Nam HS, Song D, et al. Importance of truncal-type occlusion in stentriever-based thrombectomy for acute stroke. Neurology 2016;87:15421550.

32. Baek JH, Kim BM, Kim DJ, Heo JH, Nam HS, Yoo J. Stenting as a rescue treatment after failure of mechanical thrombectomy for anterior circulation large artery occlusion. Stroke 2016; 47:2360-2363.

33. Suh HI, Hong JM, Lee KS, Han M, Choi JW, Kim SJ, et al. Imaging predictors for atherosclerosis-related intracranial large artery occlusions in acute anterior circulation stroke. J Stroke 2016;18:352-354.

34. Lee JS, Hong JM, Lee KS, Suh HI, Demchuk AM, Hwang YH, et al. Endovascular therapy of cerebral arterial occlusions: intracranial atherosclerosis versus embolism. J Stroke Cerebrovasc Dis 2015;24:2074-2080.

35. Lee JS, Hong JM, Lee KS, Suh HI, Choi JW, Kim SY. Primary stent retrieval for acute intracranial large artery occlusion due to atherosclerotic disease. J Stroke 2016;18:96-101.

36. Kang DH, Kim YW, Hwang YH, Park SP, Kim YS, Baik SK. Instant reocclusion following mechanical thrombectomy of in situ thromboocclusion and the role of low-dose intra-arterial tirofiban. Cerebrovasc Dis 2014;37:350-355.

37. Seo JH, Jeong HW, Kim ST, Kim EG. Adjuvant tirofiban injection through deployed solitaire stent as a rescue technique after failed mechanical thrombectomy in acute stroke. Neurointervention 2015;10:22-27.

38. Goh DH, Jin SC, Jeong HW, Ha SY. Mechanical solitaire thrombectomy with low-dose booster tirofiban injection. Neurointervention 2016;11:114-119.

39. Okawa M, Tateshima S, Lieveskind D, Rao N, Jahan R, Gonzalez $\mathrm{N}$, et al. Early loss of immediate reperfusion while stent retriever in place predicts successful final reperfusion in acute ischemic stroke patients. Stroke 2015;46:3266-3269.

40. Rha JH, Saver JL. The impact of recanalization on ischemic stroke outcome: a metaanalysis. Stroke 2007;38:967-973.

41. Yoon W, Kim SK, Park MS, Kim BC, Kang HK, et al. Endovascular treatment and the outcomes of atherosclerotic intracranial stenosis in patients with hyperacute stroke. Neurosurgery 2015;76:680-686.

42. Levy El, Mehta R, Gupta R, Hanel RA, Chamczuk A, Fiorella D, et al. Self-expanding stents for recanalization of acute cerebrovascular occlusion. AJNR Am J Neuroradiol 2007;28:816822.

43. Zaidat 00, Wolfe T, Hussain SI, Lynch JR, Gupta R, Delap J, et 
al. Interventional acute ischemic stroke therapy with intracranial self-expanding stent. Stroke 2008;39:2393-2395.

44. Brekenfeld C, Schroth G, Mattle H, Do DD, Remonda L, Mordasini $P$, et al. Stent placement in acute cerebral artery occlusion: use of a self-expandable intracranial stent for acute stroke treatment. Stroke 2009;40:847-852.

45. Levy El, Siddiqui AH, Crumlish A, Snyder KV, Hauck EF, Fiorella DJ, et al. First food and drug administration-approved prospective trial of primary intracranial stenting for acute stroke: SARIS (stent-assisted recanalization in acute ischemic stroke). Stroke 2009;40:3552-3556.

46. Suh SH, Kim BM, Roh HG, Lee KY, Park SI, Kim DI, et al. Self- expanding stent for recanalization of acute embolic or dissecting intracranial artery occlusion. AJNR Am J Neuroradiol 2010;31:459-463.

47. Mocco J, Hanel RA, Sharma J, Hauck EF, Snyder KV, Natarajan SK, et al. Use of a vascular reconstruction device to salvage acute ischemia occlusions refractory to traditional endovascular recanalization methods. J Neurosurg 2010;112:557-562.

48. Qureshi Al, Siddiqui AM, Kim SH, Hanel RA, Xavier AR, Kirmani JF, et al. Reocclusion of recanalized arteries during intra-arterial thrombolysis for acute ischemic stroke. AJNR Am J Neuroradiol 2004;25:322-328. 